\title{
STUDY OF COMMERCIAL THERMOPLASTIC BIODEGRADABLE POLYESTER RESIN AS A SOLID WASTE MITIGATION ROUTE USING ASTM D 5988-18
}

\author{
MOHAMED WAHEED KISHK, HAJAR JAWAD KARAM, MASUMAH AL-QASSIMI, \\ AISHA ABDULLAH AL-ROWAIH, MAJED HAMEED AL-WADI \& SULTAN MAJED AL-SALEM \\ Environment and Life Sciences Research Centre, Kuwait Institute for Scientific Research, Kuwait
}

\begin{abstract}
Developing countries are faced with an overgrowing solid waste problem that various governmental bodies are trying to combat using either source mitigation or end of pipe solutions. Furthermore, the accumulation of plastic solid waste, in particular, is causing major concern to various entities around Gulf Council Countries (GCC), where various efforts are undertaken at state level to mitigate its accumulation from point sources. One such, is the development of standards for biodegradable plastics, namely comparing market available grades of oxo (pro-degradant enhanced) biodegradables against thermoplastic resin masterbatches. In this work, we have initiated such research efforts that takes into consideration governmental demands in the GCC and have considered a commercially available polyester masterbatch to study using the standard test method of the American Society of Testing and Materials D 5988-18 "Determining Aerobic Biodegradation of Plastic Materials in Soil". Laboratory controlled conditions were used to initiate the study of determining the degree and rate of aerobic biodegradation of the material in contact with soil that represents an active landfill site within the State of Kuwait. The masterbatch resin considered was previously claimed to be certified by the manufacturer in accordance with EN 17033 as a bio-based plastic derived from corn rendering the material as a modified polyester and polyactide. A pota starch (MSDS CAS No. 009005-84-9) purchased from Loba Chemie Company was used for positive control experimental runs. The soil was aerated with the compost in laboratory conditions and mixed in a 1:25 ratio (e.g. 18:450 g compost/g soil) with a moisture content of $80-100 \%$ maintained throughout the full duration of the experiment by adding distilled water. The biodegradation rate (\%) was evaluated based on the carbon evolution estimation from the stoichiometry of the degradation reaction. The reported results can be used as a comparison baseline for both standards development (for market purposes) and applicability of material as a plastic waste mitigation technique for use.
\end{abstract}

Keywords: biodegradation, polyester, starch, ASTM D 5988, waste management.

\section{INTRODUCTION}

With the increasing threat of plastic solid waste (PSW) namely due to its non-degradable nature, water clogging of soil and micro/plastics fragments distribution in environmental sinks, efforts have increased the world over to overcome this issue [1]-[3]. One of the most promising solutions to the PSW accumulation problem is the development of biodegradable plastics. This class of polymers seem to represent themselves as an advantageous solution especially in developing world countries where PSW generation is considered to be higher than other parts of the world [1], [4]. In more specific terms, Arab Gulf Council Countries (GCC) have been trying to combat this problem for the past decade or so and various research efforts have taken place with successes in developing various standards and determining the applicability of such materials to their arid environments [5]-[8]. GCC countries are also characterised by being high waste generating countries, where for instance a relatively small nation such as Kuwait produces over $200 \mathrm{ktpa}$ of PSW [3].

Biodegradability of plastics is also a matter that has been researched to a great extent in recent years [9]-[11]. There exist various standardised testing protocols that have been developed by various bodies such as the American Society of Testing and Materials (ASTM) 
and the International Standards Organization (ISO) to measure the extent of biodegradability for polymers. The majority of these tests involve soil burial, enzymatic degradation and carbon evolution measurements. For a review of such tests methods, readers are referred to Al-Salem et al. [5]. Nonetheless, it is of immense importance to have these tests mimic the reality of the region and the nature of the studied samples. To this end and following this research group's recent work in this research area [5]-[7], we have applied the standard test method of ASTM D 5988-18 "Determining Aerobic Biodegradation of Plastic Materials in Soil" on a number of biodegradable plastic blends that were prepared and compounded within our facilities. The plastics mimic those that are used on a daily basis within regional (west Asian) and international markets and have been popularized as of late namely on the Kuwaiti market. The test method has been also modified using soil that resembles landfill sites in Kuwait to determine the actual fate of such materials if they were discarded as a polymeric waste material. In addition, biodegradation has been enforced on real-life reclaimed PSW blended with pro-degradants to study the possibility of eliminating PSW using biodegradation as a waste minimization solution. To the best of our knowledge, such a study angle has not been attempted in past research efforts on such plastic blends.

\section{MATERIALS AND METHODS}

\subsection{Materials}

PSW originating from municipal sources (in films form) was outsourced from waste recyclers within Kuwait. The materials were previously characterised for type and percentile distribution as shown in [3]. Linear low density polyethylene (LLDPE) is the most common plastic film grade used the world over, and was used in this work as a $3 \mathrm{~mm}$ translucent pellets with a reported density of $0.918 \mathrm{~g} \mathrm{~cm}^{-3}$ and a melt flow index (MFI) of $2 \mathrm{~g} 10 \mathrm{~min}^{-1}$. A PDQ-M Willow Ridge Plastics (Inc.) oxo-pro-degradant additive was used in the masterbatch preparation, which has a reported Tm of $110^{\circ} \mathrm{C}$ and was used as tan pellets. A BASF Ecovio certified compostable masterbatch (thermoplastic starch, TPS) declared as a finished product was used as white translucent pellets. The masterbatch is claimed to be certified by the manufacturer as a biobased plastic (modified polyester and polylactide) with a melting point of $120^{\circ} \mathrm{C}$. Polycaprolactone (PCL) was also acquired and used as a reference biodegradable plastic material (Polysciences/CAT 19561).

\subsection{Plastic film compounding}

PSW was air blown with an air jet ( 2 bar) and were milled to $3 \mathrm{~mm}$ flakes using an industrial Tecnova S.R.L. cutting mill and pelletized to $3 \mathrm{~mm}$ pellets using a Tecnova single screw extruder $(\mathrm{L} / \mathrm{D}=30)$ at 40 bars pressure and $180 \mathrm{rpm}$. The extrusion zone temperatures were maintained between 155 and $195^{\circ} \mathrm{C}$ at die. Single screw extrusion (SSE) was performed using a Dolci extruder (L/D ratio 1/28) using $10 \mathrm{~kg}$ as masterbatch mix ratios maintained between 165 and $200^{\circ} \mathrm{C}$ for extrusion zones. A flow rate of $50 \mathrm{~kg} \mathrm{~h}^{-1}$ was kept throughout with an operating pressure of 6 bars. The study samples were compounded with the following dry weight percentages (wt./wt.\%) to mimic the grades available on the market including comparative assessment with virgin LLDPE and a 100 (wt.\%) PSW film: LLDPE (100 wt.\%), PSW (100 wt.\%), LLDPE/PDQ-M (97/3 wt.\%/wt.\%), PSW/PDQ-M (97/3 wt.\%/wt.\%), LLDPE/TPS (97/3 wt.\%/wt.\%) and PSW/TPS (97/3 wt.\%/wt.\%). TPS and PCL were used as received pellets as described below. All samples were extruded as sheets of 
$100 \mu \mathrm{m}$ thickness meeting standard market specifications and as an average of major film applications [12].

\subsection{Biodegradation test}

Biodegradation was performed based on ASTM D5988-18 [13] to evaluate the degree and rate of aerobic biodegradation of plastic materials relative to reference material in contact with soil under laboratory controlled conditions.

\subsubsection{Soil source and characterization}

A mixture of natural soil and mature compost was used as a test matrix. Natural surface soil samples $(50 \mathrm{~kg})$ was obtained locally originating from Maqwa'a area mimicking waste landfill soil [5]. The soil was used fresh (as received) to ensure presence of active microbiota after sieving it to $>2 \mathrm{~mm}$ particle size which allows the components to be well distributed. Soil was mixed local compost (sheep manure) in a 1:25 ratio. The $\mathrm{pH}$ value (in a 20 to 20 $(\mathrm{w} / \mathrm{v})$ slurry), water content (after drying for $16 \mathrm{~h}$ at $110 \pm 5^{\circ} \mathrm{C}$ ), ash content (by igniting the oven-dried sample in a furnace at $440 \pm 40^{\circ} \mathrm{C}$ ), organic matter content, water holding capacity (WHC), total carbon and nitrogen, the microbial population of the soil were measured according to standard methods of ASTM D4972-19, ASTM D2974-14, BS EN ISO 846, Dumas dynamic method and Gupta method, respectively [14]-[19]. The pH value was 7.8; water content was $3.7 \%$, ash content was $2.5 \%$ and the organic matter was $40.2 \%$.

\subsubsection{Experimental set-up}

The test was performed in triplicate for each of the technical control (desiccator that contains only the absorbing solution in a sealed air-tight system), soil blank (showing the background activity of the soil), positive reference material (to check the viability of the soil microbial community), and test materials (triplicate for each test material). Starch powder from Loba Chemie Company were employed as a reference material for the biodegradation test in the soil. The soil was weighed and mixed with compost in a 1:25 ratio (18:450 g compost/g soil) in a separate container to get a homogeneous mixture (test matrix). Thereafter, the soil was transferred to the bottom of each vessel $(150 \mathrm{~mm}$ desiccators with 4 litres internal volume equipped with an air-tight seal). The final soil water content was adjusted to $12.7 \%$ (about $50 \%$ of the water holding capacity). Approximately $600 \mathrm{mg}$ of test material (sufficient quantity to yield enough carbon dioxide that allows for better monitoring of the actual biodegradation rate for the test materials), in the form of pellets or films that were cut out square-shaped coupons with a dimension of approximately $2 \mathrm{~cm}^{2}$. The mass was recorded for each sample. To improve the contact of the tested material with the microbiota, the powder/pellets were mixed thoroughly into the soil. In the case of film coupons, the tested material was evenly spread and pressed with a spatula in the soil. Each vessel contained two $100 \mathrm{~mL}$ beakers, one with $20 \mathrm{ml}$ of potassium hydroxide $(0.5 \mathrm{~N} \mathrm{KOH})$ and the other containing $50 \mathrm{ml}$ of distilled water and were placed on the perforated plate inside the vessel.

\subsection{3 $\mathrm{CO}_{2}$ analysis}

The $\mathrm{CO}_{2}$ analysis was measured based on the $\mathrm{CO}_{2}$ evolved in each vessel by analysing its reaction with $\mathrm{KOH}$ to produce potassium carbonate $\left(\mathrm{K}_{2} \mathrm{CO}_{3}\right)$ and unreacted $\mathrm{KOH}$. The titration was performed with hydrochloric acid $(0.5 \mathrm{~N} \mathrm{HCl})$ to a phenolphthalein end-point according to the following equations:

$$
2 \mathrm{KOH}+\mathrm{CO}_{2} \rightarrow \mathrm{K}_{2} \mathrm{CO}_{3}+\mathrm{H}_{2} \mathrm{O},
$$




$$
\begin{gathered}
\mathrm{KOH}+\mathrm{HCl} \rightarrow \mathrm{KCl}+\mathrm{H} 2 \mathrm{O} \text { (at } \mathrm{pH} \text { equals to } 7), \\
\mathrm{K}_{2} \mathrm{CO}_{3}+\mathrm{HCl} \rightarrow \mathrm{KHCO}_{3}+\mathrm{KCl} \text { (at } \mathrm{pH} \text { equals to } 8.5 \text { ). }
\end{gathered}
$$

The amount of $\mathrm{CO}_{2}$ produced by a test material was calculated by the difference (in $\mathrm{ml}$ of titrant) between the test and blank vessels. The volume of $\mathrm{HCl}$ consumed in $\mathrm{ml}$, was used to calculate the molar concentration $(\mathrm{mmol})$ of $\mathrm{CO}_{2}$. The readers are referred Al-Salem et al. [5] for further methodological details; and Fig. 1 for a pictorial depiction of the test set-up.

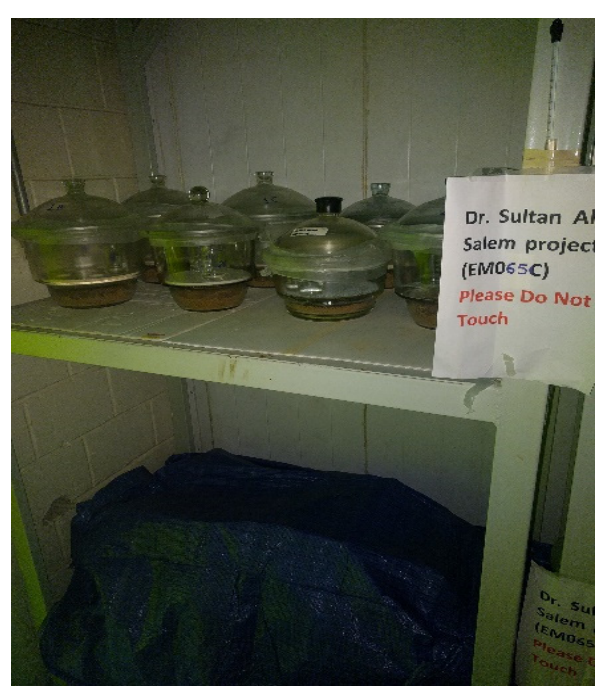

(a)

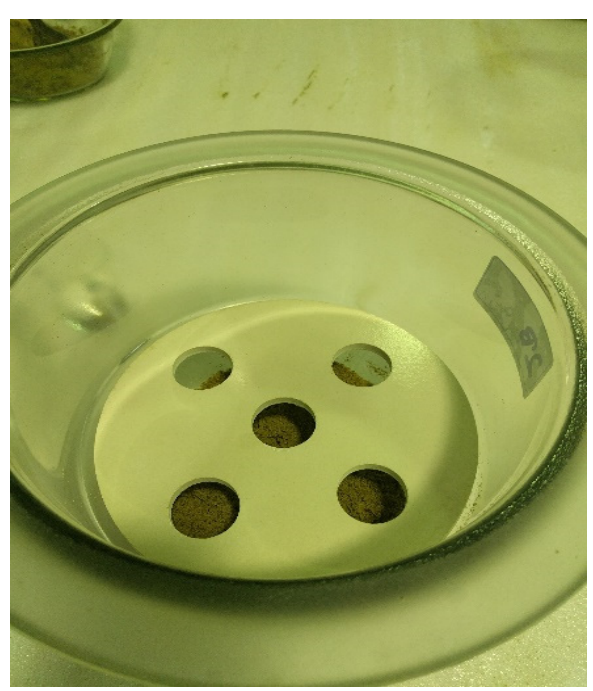

(b)

Figure 1: (a) Dark room set-up for biodegradation test; and (b) Open glass desiccator (4 litres) used in biodegradation tests.

\section{RESULTS AND DISCUSSIONS}

To be able to determine the extent of biodegradation for the materials used, various parameters must be observed within the experimental matrix. These will include the rate of biodegradation, the nature and experimental error of the results and the carbon evolution with respect to the study time. The total experimental time for the test method is given at a maximum by the standard protocol test methods followed as six months in total. Fresh soil was used to assure that the soil microbiota is of maximum diversity and of high activity in a suitable degrading environment. The initial $\mathrm{pH}$ value for the soil used was found to be 7.8. This indicates that the media if of a weak alkali nature and has the potential to contain a typical microbial population [13]. The total organic content of the soil was estimated at $40.2 \%$ which indicates that it is of a suitable ratio to maintain microbial growth. The water content was adjusted to about $50 \%$ of the maximum WHC and was controlled throughout the experimental period as the water availability is a crucial parameter for the microbial growth and metabolic activity and having a significant effect on the biodegradation processes [20], [21]. The total number of microorganisms (including bacteria and fungi) in the soil was $4 \times 10^{6} \mathrm{cfu}$ per gram of the test matrix (estimated by determining average colony forming units, cfu, using spread plate method). ASTM D5988 was used to assess the degree of aerobic biodegradation on the compound films in soil by measuring the evolved $\mathrm{CO}_{2}$ as a function of 
exposure time to determine the extent of their biodegradability, as it is one of the latest and approved standard methods. Based on previous work [13] and the recommendation of the ASTM, a KOH trap was used as an alternative to barium hydroxide solution $\left(\mathrm{Ba}(\mathrm{OH})_{2}\right)$ to facilitate the diffusion of $\mathrm{CO}_{2}$ into the absorbing medium. The biodegradation was calculated from the ratio between the net $\mathrm{CO}_{2}$ production and the theoretical $\mathrm{CO}_{2}$ based on the carbon content. The plastic material was tested in the form of pellets and film as it is acceptable for test specimens to be introduced in the form of films, pieces, fragments, powders, or shaped articles [13]. Biodegradation extent is shown in Fig. 2. Each material studied is represented with respect to real-experimental time (in days) stemming from the mean value of three triplicate runs.

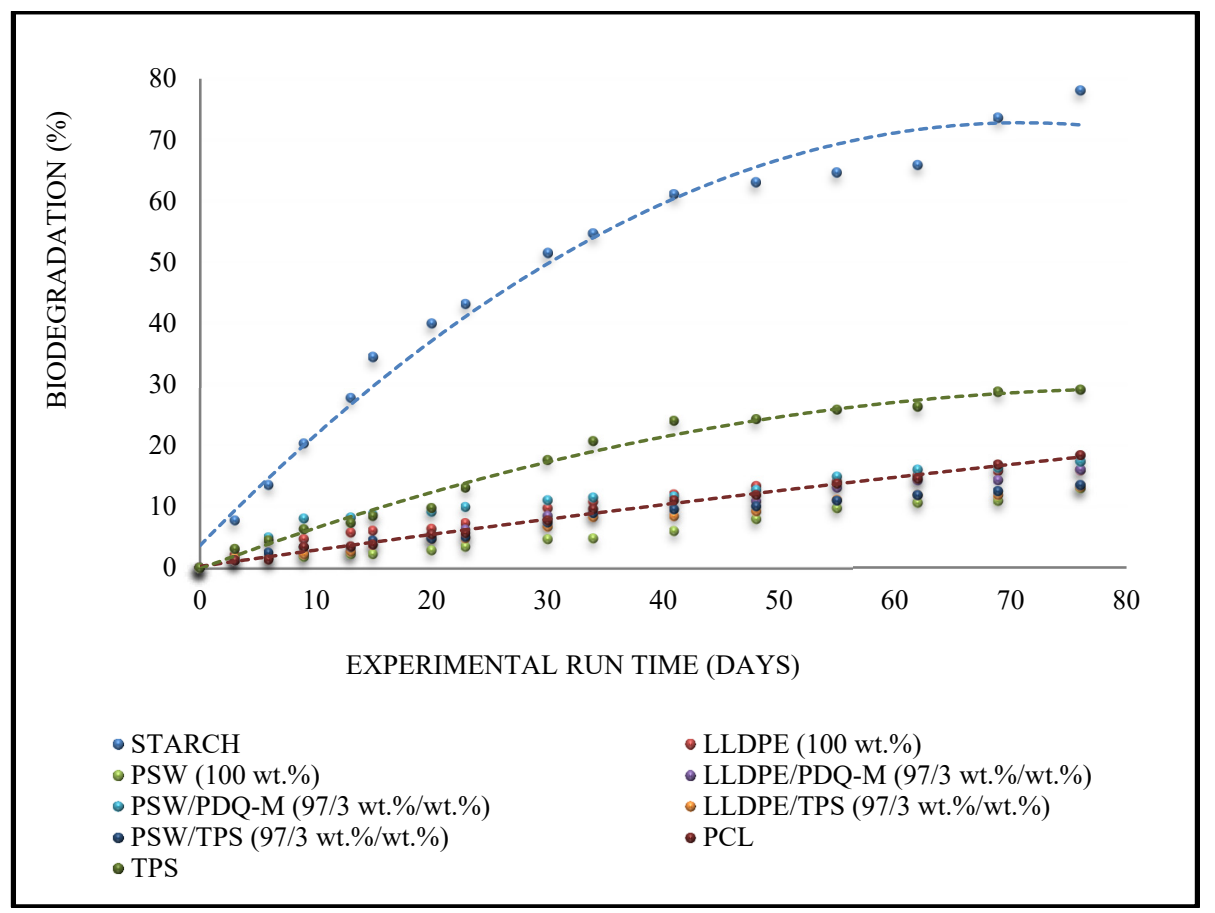

Figure 2: Biodegradation rate (\%) estimated (to date) for 76 days of experimental runtime.

The starch reference material was the highest in biodegradation rate as anticipated at the start of the experimental run. The material exhibited over $50 \%$ of degradation rate in less than 50 days of continuous monitoring. The starch material also showed a percentage of biodegradability of $>70 \%$ after 70 days which meets the validation criteria for the test method [13]. This on the other hand indicates that the soil was active and the test are valid. Furthermore, the TPS material was the second in-line, in terms of biodegradation rate (Fig. 2). The mineralization for TPS reached $29 \pm 0.28 \%$ in 76 days, rendering it second highest in degradation rate to the starch $(78 \pm 0.44 \%)$. PCL, the biodegradable polymer used as well for comparative reasons, was third in the depicted results showing a rate of biodegradation of some $18.3 \pm 0.22 \%$ by the end of the testing duration which is noted to be a delayed response considering the cycle for this materials nature. This also indicates that the 
soil conditions aforementioned might not be suitable for such materials under certain aridland conditions. The humidity levels are also suspected to be a crucial element for the degradation of PCL under certain conditions. Šerá et al. [22] showed that the temperature of the incubation temperature from 25 to $37^{\circ} \mathrm{C}$, increases the biodegradation rate of certain biodegradable plastics. At this stage, it should be noted that ASTM D 5988 is somewhat equivalent to the standard test protocol of ISO 17556. Mater-Bi HF03V1, a commercially available TPS made with similar characteristics to the TPS used in this work was studied using similar test conditions by Pischedda et al. [23]. At 15 and $20^{\circ} \mathrm{C}$, the mineralisation (biodegradation rate) was estimated at some $20 \%$ after 100 days which is considerably lower than the estimated rate in this work. The behaviour observed in the aforementioned curve could also be explained by the rapid increase in microbial population at the beginning of the test period are readily available for assimilation which get depleted with experimental time [24]. Fig. 3 shows the degradation rate of the commercial plastics considered in this work.

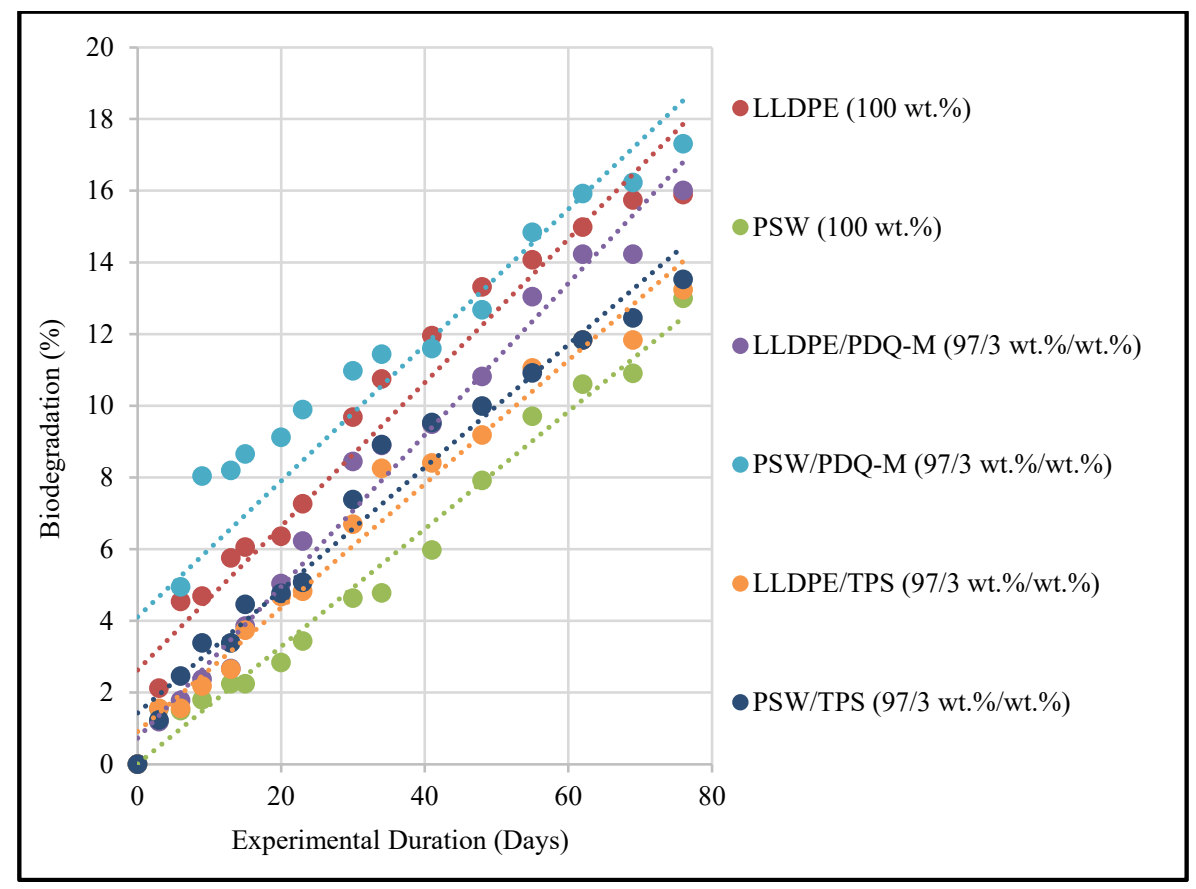

Figure 3: Biodegradation rate (\%) estimated for the experimental run-time showing commercial polyolefin plastics considered.

The least favourable material in terms of biodegradation rate after 76 days of testing, was the PSW on its own used in the form of films simulating discarded waste buried in landfill sites. The material showed a $12.9 \%$ rate of biodegradation which was lower than the virgin LLDPE used in this work $(15.8 \%)$. This could be attributed to the fact that the PSW was exposed to more heating cycles/loops that increases its crystallinity and hardens its structure compared to the virgin LLDPE. On the other hand, initial testing trials of the concept of inducing the biodegradation rate of PSW proved viable. This is supported by the fact that the PSW filled with pro-degradant (by $3 \mathrm{wt} . \%$ ) was degrading faster than the other materials 
considered in this study. The biodegradation rate of the PSW/PDQM (97/3\%), LLDPE/PDQM (97/3\%), and LLDPE (100\%) films was $17.3 \pm 0.33 \%, 16 \pm 0.12 \%$ and $15.89 \pm 0.23 \%$, respectively.

\section{CONCLUSION}

In the context of environmental management, it is almost a certainty that plastic solid waste accumulation and generation, is favoured and serious mitigation measures should be taken to combat it. In this work, plastic and virgin commercial grade plastics were tested after studying their biodegradability with both a pro-degradant additive and a thermoplastic starch material. The materials were also compared to biodegradable polymers and resins. The test method of ASTM D 5988-18 was used to study the biodegradation using a soil matrix that simulates landfill environments in arid-lands. Rigorous testing of the soil material was also conducted to have a clear overview of the testing environment. In terms of the materials tested (to date), the pro-degradant additive that rendered both the virgin linear low density polyethylene and plastic solid waste, made it more susceptible to biodegradation and fragmentation. This is when compared to the other tested material in this work excluding the naturally (as is) biodegradables. This indicates that it is possible to consider the mechanical recycling of plastic waste with the addition of pro-degradants to make them more favourable to biodegradation. There is a certain concern when it comes to interrupting these preliminary results obtained in this work. The main barrier is to assess the eco-friendly design and aspect of having metal added pro-degradants that might increase the toxicity of the plastics when exposed to high humidity environments. Therefore, and since the materials tested in this work with starch based components show promising results, it might be worth in the future to consider a comparative assessment of their life cycle or impact assessment works.

\section{ACKNOWLEDGEMENT}

The authors are grateful to the Kuwait Institute for Scientific Research (KISR) for funding research project EM065K.

\section{REFERENCES}

[1] Yang, H.S., Yoon, J.S. \& Kim, M.N., Dependence of biodegradability of plastics in compost on the shape of specimens. Polymer Degradation and Stability, 87(1), pp. 131-135, 2005.

[2] Al-Salem, S.M., Uddin, S. \& Lyons, B., Evidence of microplastics (MP) in gut content of major consumed marine fish species in the State of Kuwait (of the Arabian/Persian Gulf). Marine Pollution Bulletin, 2020.

[3] Al-Salem, S.M., Abraham, G., Al-Qabandi, O.A. \& Dashti, A.M., Investigating the effect of accelerated weathering on the mechanical and physical properties of high content plastic solid waste (PSW) blends with virgin linear low density polyethylene (LLDPE). Polymer Testing, 46, pp. 116-121, 2015.

[4] Kaza, S., Yao, L., Bhada-Tata, P. \& Van Woerden, F., What a Waste: A Global Snapshot of Solid Waste Management to 2050, World Bank: Washington, DC. DOI: 10.1596/978-1-4648-1329-0, 2018.

[5] Al-Salem, S.M., Sultan, H.H., Karam, H.J. \& Al-Dhafeeri, A.T., Determination of biodegradation rate of commercial oxo-biodegradable polyethylene film products using ASTM D 5988. Journal of Polymer Research, 26(7), p. 157, 2019. 
[6] Al-Salem, S.M., Al-Hazza'a, A., Karam, H.J., Al-Wadi, M.H., Al-Dhafeeri, A.T. \& Al-Rowaih, A.A., Insights into the evaluation of the abiotic and biotic degradation rate of commercial pro-oxidant filled polyethylene (PE) thin films. Journal of Environmental Management, 250, 109475, 2019.

[7] Al-Salem, S.M. et al., Thermal response and degressive reaction study of oxobiodegradable plastic products exposed to various degradation media. International Journal of Polymer Science, 9612813, 2019.

[8] Abdallah, M., Shanableh, A., Shabib, A. \& Adghim, M., Financial feasibility of waste to energy strategies in the United Arab Emirates. Waste Management, 82, pp. 207219, 2018.

[9] Castro-Aguirre, E., Auras, R., Selke, S., Rubino, M. \& Marsh, T., Insights on the aerobic biodegradation of polymers by analysis of evolved carbon dioxide in simulated composting conditions. Polymer Degradation and Stability, 1(137), pp. 251-271, 2017.

[10] Oberbeckmann, S., Loeder, M.G., Gerdts, G. \& Osborn, A.M., Spatial and seasonal variation in diversity and structure of microbial biofilms on marine plastics in Northern European waters. FEMS Microbiology Ecology, 90(2), pp. 478-492, 2014.

[11] Großkopf T. \& Soyer O.S., Synthetic microbial communities. Current Opinion in Microbiology, 18, pp. 72-77, 2014.

[12] Al-Salem, S.M., Influential parameters on natural weathering under harsh climatic conditions of mechanically recycled plastic film specimens. Journal of Environmental Management, 230, pp. 355-365, 2019.

[13] ASTM International, ASTM D5988-18, Standard test method for determining aerobic biodegradation of plastic materials in soil. ASTM International: West Conshohocken, PA, 2018. www.astm.org/Standards/D5988.html. Accessed on: 22 Nov. 2019.

[14] ASTM International, D4972-19, Standard test methods for $\mathrm{pH}$ of soils. ASTM International: West Conshohocken, PA, 2019.

DOI: https://doi.org/10.1520/D4972-19.

[15] ASTM International, D2974-14, Standard test methods for moisture, ash, and organic matter of peat and other organic soils. ASTM International: West Conshohocken, PA, 2014. DOI: https://doi.org/10.1520/D2974-14.

[16] British Standards (BS), ISO 846, Implementation of the International Standards Organization, Plastics: Evaluation of the action of microorganisms, 2019. https://doi.org/10.3403/30367618.

[17] Bremner, J.M., Nitrogen-total. Methods of Soil Analysis: Part 3 Chemical Methods, eds D.L. Sparks, A.L. Page, P.A. Helmke, R.H. Loeppert, P.N. Soltanpour, M.A. Tabatabai, C.T. Johnston \& M.E. Sumner, Soil Science Society of America and American Society of Agronomy: Madison, WI, pp. 1085-1121, 1996.

[18] Krotz, L. \& Giazzi, G., Elemental analysis: CHNS/O characterization of polymers and plastics, Application Note 42230, Thermo Fisher, 2016.

https://assets.thermofisher.com/TFS-Assets/CMD/Application-Notes/an-42230-oeachnso-polymers-plastics-an42230-en.pdf.

[19] BS 7755-3.8, Soil quality. Chemical methods. Determination of organic and total carbon after dry combustion (elementary analysis), 1995.

DOI: https://doi.org/10.3403/00577903.

[20] Grima, S., Bellon-Maurel, V., Feuilloley, P. \& Silvestre, F., Aerobic biodegradation of polymers in solid-state conditions: A review of environmental and physicochemical parameter settings in laboratory simulations. Journal of Polymers and the Environment. 8(4), pp. 183-195, 2000. 
[21] Briassoulis, D. \& Dejean, C., Critical review of norms and standards for biodegradable agricultural plastics, Part I: Biodegradation in soil. Journal of Polymers and the Environment, 18(3), pp. 384-400, 2010.

[22] Šerá, J., Serbruyns, L., De Wilde, B. \& Koutný, M., Accelerated biodegradation testing of slowly degradable polyesters in soil. Polymer Degradation and Stability, 171, 109031, 2020.

[23] Pischedda, A., Tosin, M. \& Degli-Innocenti, F., Biodegradation of plastics in soil: The effect of temperature. Polymer Degradation and Stability, 170, 109017, 2019.

[24] Castro-Aguirre, E., Auras, R., Selke, S., Rubino, M. \& Marsh, T., Insights on the aerobic biodegradation of polymers by analysis of evolved carbon dioxide in simulated composting conditions. Polymer Degradation and Stability, 137, pp. 251-271, 2017. 